\title{
Are cities prepared for climate change? An analysis of adaptation readiness in 104 German cities
}

\author{
Antje Otto $^{1}$ (D) Christian Göpfert ${ }^{2}$ (D) . Annegret H. Thieken ${ }^{1}$ (D)
}

Received: 19 May 2020 / Accepted: 2 September 2021

(c) The Author(s) 2021

\begin{abstract}
Cities can be severely affected by climate change. Hence, many of them have started to develop climate adaptation strategies or implement measures to help prepare for the challenges it will present. This study aims to provide an overview of climate adaptation in 104 German cities. While existing studies on adaptation tracking rely heavily on self-reported data or the mere existence of adaptation plans, we applied the broader concept of adaptation readiness, considering five factors and a total of twelve different indicators, when making our assessments. We clustered the cities depending on the contribution of these factors to the overall adaptation readiness index and grouped them according to their total score and cluster affiliations. This resulted in us identifying four groups of cities. First, a pioneering group comprises twelve (mainly big) cities with more than 500,000 inhabitants, which showed high scores for all five factors of adaptation readiness. Second, a set of 36 active cities, which follow different strategies on how to deal with climate adaptation. Third, a group of 28 cities showed considerably less activity toward climate adaptation, while a fourth set of 28 mostly small cities (with between 50,000 and 99,999 inhabitants) scored the lowest. We consider this final group to be pursuing a 'wait-and-see' approach. Since the city size correlates with the adaptation readiness index, we recommend policymakers introduce funding schemes that focus on supporting small cities, to help them prepare for the impact of a changing climate.
\end{abstract}

Keywords Adaptation tracking · Adaptation plans · Cluster analysis · City ranking · Urban climate policy $\cdot$ Germany

Antje Otto

anotto@uni-potsdam.de

1 Institute of Environmental Science and Geography, University of Potsdam, Karl-Liebknecht-Straße 24-25, 14476 Potsdam, Germany

2 Technical University of Munich, Institute of Energy Efficient and Sustainable Design and Building (ENPB), Arcisstr. 21, 80333 Munich and City of Würzburg, Rückermainstraße. 2, 97070 Würzburg, Germany 


\section{Introduction}

Despite its global relevance, cities are often seen as key actors in governing climate change (Bausch and Koziol 2020; de Coninck et al. 2018; Fuhr et al. 2018; Romero-Lankao 2012; UN-Habitat 2011). Approximately 55\% of the world's population currently lives in urban areas, a percentage which is expected to increase further (United Nations 2018). Although studies initially focused on cities' mitigation activities (Castán Broto and Bulkeley 2013; Schüle et al. 2016), there is a growing scientific and practical interest in climate change adaptation in municipalities (Alber and Kern 2008; Davoudi et al., 2009; Knieling and Roßnagel 2014; Wamsler et al. 2013). Among other things, the high concentration of people and assets in urban areas implies they are more exposed to the impacts of climate change, including sea-level rise for coastal cities, and extreme weather events such as heavy rainfall or heatwaves. Such events are expected to increase in frequency, intensity and/or persistence in many parts of the world (IPCC et al. 2014). Furthermore, their impacts are exacerbated by urban development, urban sealing and the urban heat island effect (Ellena et al. 2020; IPCC et al. 2014; Kareem et al. 2020; Ye et al. 2021). Thus, climate change adaptation, including the planning, implementation and evaluation of adaptation measures such as 'grey' infrastructures or nature based solutions, has emerged as a task for many municipalities around the globe (Biagini et al. 2014; Dhar and Khirfan 2017; Geneletti and Zardo 2016; Hintz et al. 2018; Meng et al. 2020; Voskamp and Van de Ven 2015; Wamsler et al. 2020). Adaptation also involves non-structural measures, such as risk communication and educating the public about how to act during extreme weather events (e.g. Kox and Thieken 2017; Kuhlicke et al. 2020; Brink and Wamsler 2019).

These developments have thrown up questions around how and by whom climate adaptation is governed, which factors hinder or support active and successful climate adaptation and if urban adaptation is sufficiently implemented (Biesbroek et al. 2013; Göpfert et al. 2020; Van der Heijden 2019). Concerning the latter question, Aguiar et al. $(2018,39)$ reason that the 'understanding of the scale and depth of current adaptation activities and the preparedness of governance systems' in cities is still limited. In a literature review on urban adaptation governance, Van der Heijden (2019, p. 2) points out that cities are partly perceived 'as saviours of the planet in the face of climate change' and concludes among other things that 'the gap that was observed a decade ago between the high levels of policy rhetoric about urban climate governance and the reality of limited activity' (p. 3) remains an essential research area. He argues that despite some rise in municipal climate action, traditional tasks (such as housing and waste disposal) are more urgent for many cities, and pronounced climate actions are limited to a few frontrunner cities. In line with this, Castán Broto and Westman (2020, p. 11) call for a better understanding of the degree and sufficiency of adaptation in cities.

This paper deals with these research limitations drawing on adaptation tracking literature.

Adaptation tracking aims to 'systematically identify, characterize and compare adaptation' (Ford et al. 2015, 967) by assessing progress across, e.g. cities over time. Amongst other things, this can help to assign funding and resources and to decide on adjustments in adaptation (Olazabal et al. 2019a; Biesbroek et al. 2018). On the city level, many studies tracking adaptation analyse the existence and, in part, the content of climate adaptation plans (also termed strategies or concepts) and use these as general indicators for progress (Reckien et al. 2014; 2018; Heidrich et al. 2013; Olazabal et al. 2014). However, Reckien et al. (2015) point out that examining these plans can only provide us with a limited 
picture of progress, because we also need to examine how they are being implemented. We therefore apply the 'adaptation readiness' approach (Ford and King 2015; Ford et al. 2017; Tilleard and Ford 2016), which '[...] is concerned with examining actual experiences with planning for adaptation and seeks to characterize whether human systems are prepared and ready to "do adaptation"” (Ford and King 2015, 505). So far, to our knowledge, this approach has not been applied to a larger number of cities. Ford and King (2015) also call for studies to evaluate the approach's challenges and contributions to adaptation science, which we address here by applying it to more than 100 German cities.

Germany has a long and stable history of national support for climate mitigation and activities in the field of climate adaptation (in contrast to, e.g. the USA or Australia). At the national level, the German Adaptation Strategy was published in 2008 and substantiated in the Action Plan for Adaptation in 2011 (Klostermann et al. 2018). Despite different funding sources and various research projects targeting the local level, however, it never became compulsory for cities to develop local climate adaptation plans, as is the case in Denmark and France (Heidrich et al. 2016). Thus, engaging in both climate mitigation and adaptation—using this specific jargon—at the municipal level 'is considered as a voluntary task and municipalities have the freedom to choose whether to become active or not and "how" such measures should be implemented' (Bulkeley and Kern 2006, 2240). A few studies have already analysed the adaptation plans of German cities as a way of trying to assess progress (Reckien et al. 2014; 2018; Kind and Sartison 2017; Hasse and Willen 2019). Their findings differ depending on the city sample, the timing of the analysis and the definition of what counts as an adaptation plan. Nonetheless, several studies emphasize that bigger cities tend to draft an adaptation plan earlier than smaller cities, which might not have a plan at all (Kind and Sartison 2017; Heidrich et al. 2013). Thus, this paper examines 104 cities of different sizes but similar governance structures and explores the effect of city size on adaptation readiness.

This paper contributes to the following research questions: How well prepared are 104 German cities for climate adaptation? Which similarities and differences can be detected between the adaptation readiness of these cities and (how) can they be grouped according to their adaptation engagements? We address these questions with a focus on heat and pluvial rain and follow two underlying research aims. First, by applying adaptation readiness for the first time to a large number of cities, we aim to contribute to the international literature on adaptation tracking. Second, by extending the analysis beyond adaptation plans and, thus providing a broader picture of how active cities are in this area, we seek to add to the urban adaptation literature concerning the 'implementation gap' (e.g. van der Heijden 2019).

\section{Concept: adaptation tracking and the adaptation readiness approach}

Adaptation tracking has developed-in the shadow of mitigation tracking - 'as a means of evaluating the effectiveness of adaptation support, informing governance at various levels on adaptation needs, justifying funding allocation and communicating to the public on adaptation' (Ford et al. 2013). There are two main challenges in tracking adaptation: First, it is very difficult to define what successful climate adaptation encompasses: it differs between places, might only become evident in the far future, is intertwined with other policies and might be debated among different stakeholders (Berrang-Ford et al. 2019; 
Ford et al. 2013, 2015). Hence, adaptation tracking studies focus instead on investigating preparedness, processes and policies instead of outcomes (Ford et al. 2013; Olazabal et al. 2019a). Second, easily measurable metrics are missing and data are rarely consistent, coherent, comparable or comprehensive, as Ford and Berrang-Ford (2016) underline. Thus, studies often rely either on self-reported data or on counting the existence of adaptation plans. However, self-reported data might overemphasize positive progress (Ford et al. 2015) and depend in their extent not just on adaptation activities but also on resources and reporting accuracy (Ford et al. 2013). Counting the existence of plans-as important as plans might be for strategic goal and priority setting - is no guarantee that adaptation activity is occurring (Olazabal et al. 2019a) and adaptation activities are possible without an overarching adaptation strategy (Reckien et al. 2015). Furthermore, as adaptation becomes more common, many cities will already have plans and proceed from the stages of assessment and planning to the stages of action and monitoring (Wamsler 2015). Therefore, the differences among very active cities might shift to the implementation, monitoring and revising of plans and not just focus on their existence. However there have been few studies into implementation and data are difficult to find and analyse (Olazabal et al. 2019b).

Despite these challenges, a fast-growing literature compares the adaptation progress between (mostly big) cities on various levels (Aguiar et al. 2018; Araos et al. 2016; Dulal 2019; Le 2020; Reckien et al. 2018; 2014; Heidrich et al. 2013; Olazabal et al. 2014, 2019b; Olazabal and Ruiz De Gopegui 2021; Shi et al. 2015; Singh et al. 2021). ${ }^{1}$ Apart from a small number of leaders, this literature often shows that urban adaptation is still at an early stage: many cities are not at all engaged in the area, and the active ones are often in phases of scoping and planning instead of implementing and monitoring. Araos et al.'s (2016) study of 401 metropolises with more than 1 million inhabitants across the world found that just $15 \%$ were taking adaptation actions and $18 \%$ are planning towards adaptation. In Europe, Reckien et al. (2018) found that only $26 \%$ of 885 cities had developed an adaptation plan and $17 \%$ have a joint plan covering both adaptation and mitigation. Generally speaking, active cities are big (Araos et al. 2016; Reckien et al. 2018), located in highincome countries (Olazabal et al., 2019b) and/or countries in which the central government supports adaptation (Dulal 2019), and-within Europe-tend to be in the central and northern states (Reckien et al. 2014; 2018).

A few studies have analysed progress in German cities by looking at the existence of adaptation plans. Kind and Sartison (2017) state that 64\% (49 out of 76) of cities with more than 100,000 inhabitants had published a plan (38) or were currently working on a plan (11), while Reckien et al. (2018) find that 28\% (35 out of 125) of cities included in the Urban Audit sample offered by Eurostat ${ }^{2}$ possessed an adaptation plan. Hasse and Willen (2019) conclude that a municipal adaptation plan exists in $18 \%$ of the 249 German cities that responded to their survey. Still, data show that bigger cities tend to draft an adaptation plan earlier than smaller cities (Kind and Sartison 2017).

Approaches that examine adaptive capacity, adaptation readiness and adaptation policy credibility can provide a broader assessment of progress. They each aim to identify the extent to which specific municipalities or countries can push adaptation, but their focus

\footnotetext{
1 Alongside this, there are diverse resilience indices (Cai et al. 2018) and various assessment tools for municipalities to estimate their level of risks, vulnerability, adaptation and/or resilience and use this to inform future adaptation actions (e.g. the city resilience index, the urban adaptation support tool or the UKCIP Adaptation Wizard).

2 See https://ec.europa.eu/eurostat/web/regions-and-cities
} 
differs. Adaptive capacity deals with the area's potential and ability to adapt and therefore examines various socio-economic and bio-physical resources, such as financial and technological resources (Carter et al. 2015; Engle 2011; Tilleard and Ford 2016). However, as Ford (2017) pointed out, high levels of capacity might not transform directly into adaptation progress, because other barriers may get in the way. The adaptation readiness approach aims to overcome this blind spot by considering the existence of supportive measures and adaptive actions already taken or planned, such as publishing adaptation plans or taking part in adaptation networks. The approach seeks to identify the preparedness of an entity like a city to adapt and hence estimates whether it is 'ready' to deal with the consequences of climate change. The results can be used as a proxy to track adaptation (Ford and King 2015; Ford et al. 2017; Tilleard and Ford 2016).

So far, adaptation readiness has been applied to analyse the adaptation preparedness of single cases, such as a territory in the Canadian Arctic (Ford et al. 2017), the urban area of Dhaka (Aaros et al. 2017) and the Seychelles (Khan and Amelie 2015). It has also been used to compare transboundary river basins (Tilleard and Ford 2016) and South East Asian countries (Salamanca and Nguyen 2016). These studies assessed the status of adaptation in detail, highlighted the respective strengths and challenges of current adaptation activity, provided lessons for other areas and identified a baseline against which future studies can monitor progress. So far, to our knowledge, the approach has not been applied to a larger number of cities. Indeed, Ford and King (2015) call for pilot applications to evaluate the approach's challenges and contributions to adaptation science, which we want to address here.

In order to capture the adaptation readiness of human systems, Ford and King (2015) consider six factors which previous studies have commonly identified as influencing adaptation activity: (1) political leadership for adaptation; (2) institutional organization for adaptation; (3) adaptation decision making and stakeholder engagement; (4) availability of usable science to inform decision-making; (5) funding for adaptation planning, implementation and evaluation; and (6) public support for adaptation (for a detailed description and the reasoning behind these factors, as well as for examples of indicators, see Ford and King (2015) and Tilleard and Ford (2016)). Although these factors overlap, by assessing each one individually, we can undertake a systematic analysis of adaptation readiness. In cases where an entity such as a country or city does score high in adaptation readiness, we can expect that adaptation is likely to be implemented; vice versa, low scores hint at few upcoming adaptive actions. In addition to drawing comparisons within the sample, this systematic approach also provides information on both well-established and lagging factors within a single entity. These findings can support prioritization processes for further adaptation efforts.

To our knowledge, the adaptation readiness approach has not been used to compare a larger number of cities. Thus, we tailored it to the specific circumstances of our study.

\section{Methods}

\subsection{Empirical operationalization of the adaptation readiness of 104 cities}

For this study, which compares adaptation readiness for the first time among a large number of cities, our sample includes three official types of German cities classified by their size (BBSR 2017). These are big cities (with more than 500,000 inhabitants), medium-sized 


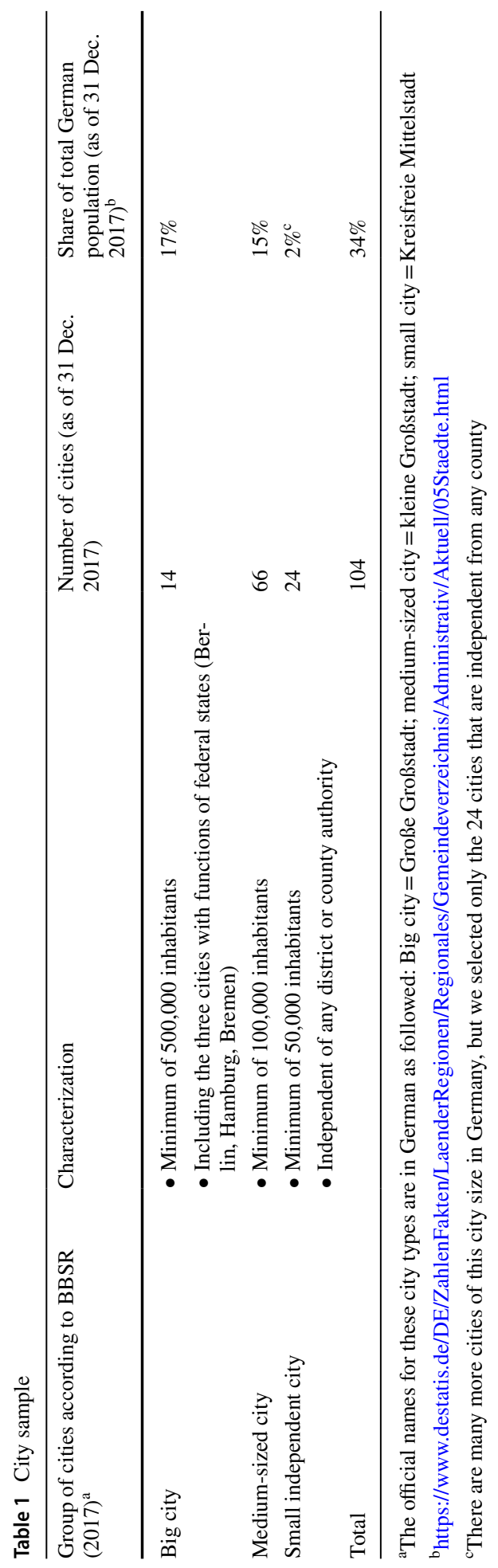




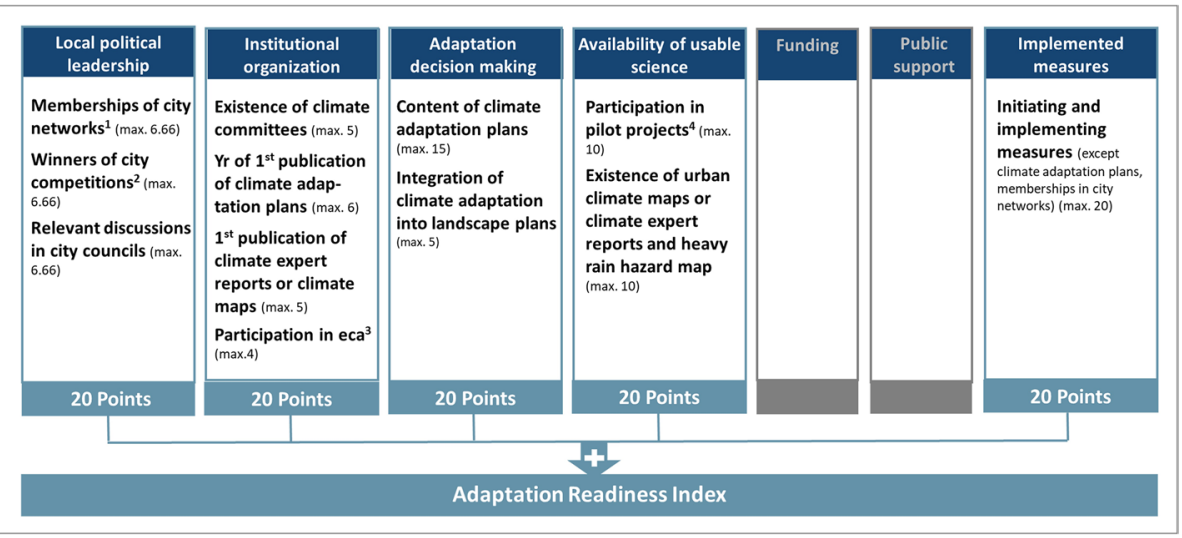

Fig. 1 Overview of factors and indicators included in the adaptation readiness index. (1) City networks included climate alliance, covenant of mayors, ICLEI. (2) City competitions included climate active municipality ('Klimaaktive Kommune' organized by the Federal Ministry for the Environment and the German Institute of Urban Affairs) and Blue Compass ('blauer Kompass' organized by the Federal Environment Agency). (3) European Climate Action Award. (4) Pilot project cluster included 'Klimazwei and 'Klimzug' (both funded by the Federal Ministry of Education and Research) as well as 'MORO' and 'ExWost' (both funded by the Federal Ministry of the Interior)

cities 100,000-500,000 inhabitants) and small cities (50,000-99,999 inhabitants, see Table 1). To ensure comparability, we restricted the small cities to those that are independent of a county (kreisfrei in German). These small cities perform all municipal functions within their areas; because responsibilities are not allocated to another tier of local government (such as a county or district), they have the same administrative scope as big cities in Germany. In total, we examined 104 cities, which contain 34\% of Germany's population (as of 31 Dec 2017; for a list of all cities, see Supplementary 1).

We used the six factors in the adaptation readiness approach (Ford and King 2015) as a framework and started by collecting possible indicators based on information from the literature and discussions with experts. We defined three criteria that indicators needed to meet in order to be included in our estimations. (A) The indicator must be relevant for estimating the state of climate adaptation. (B) It must be possible to obtain data, ideally for all 104 cities but certainly for most of them, within a reasonable timeframe. (C) The data must be openly accessible so that the study could be replicated later on and results could be compared. We therefore looked for indicators or data that were publicly available and decided against a survey or expert interviews.

We discussed the relevance of various indicators in a cooperative project setting, which involved scientists working in the field and climate adaptation practitioners from city administrations. These discussions resulted in us specifying some indicators, rejecting others and developing some new indicators. We also established a new factor (see Fig. 1) that takes into account the fact that many cities already implement climate adaptation projects and measures. So far, such actions are underrepresented within the adaptation readiness framework but are highly important if one of the aims is to compare entities that are not just planning but already implementing adaptation initiatives.

It was much more difficult to find data relating to some indicators than to others. Despite investing a significant amount of effort in the exercise, we discarded some potential indicators due to data unavailability (such as on funding and on public support for adaptation, see 
Supplementary 2 for details). Tilleard and Ford (2016) also report encountering challenges finding information on exactly these two factors using publically accessible datasets for transnational river basins.

In the end, out of the 22 indicators we initially considered, 10 were excluded and 12 were used to trace adaptation readiness across five factors (Fig. 1): local political leadership, institutional organization, adaptation decision-making, availability of usable science and implemented measures. Within the factor of 'institutional organization' we considered, inter alia, when the city became active, while the factor 'adaptation decision making' takes into account how broad the activities are, on the basis that cities should score better if they consider various fields of action (for details, see Supplementary 2).

We obtained the data for the indicators from various sources, such as the cities' web pages and web pages of city networks (for details, see Supplementary 2), with a cut-off date of 31 December 2018. In the case of the indicator 'existence of climate committees', we refer to and extend data from Göpfert et al. (2019). We tried to avoid data gaps and intended to include only those indicators for which we could gather data for all cities. However, there are 19 cities for which there is no data regarding the indicator 'integration of climate adaptation in landscape plans'. This is, however, the only data gap. To account for it, this indicator received a smaller weight instead of an equal weight. At the level of the five factors, there were no data gaps.

Ford and King $(2015,517)$ point out that 'our knowledge of the relationship between and among the readiness factors and adaptation actions remains in its infancy' and therefore equal weighting is reasonable. Thus, all five factors are assigned 20 points each, which adds up to a potential maximum of 100 points. In two factors, indicators are given different weights due to relevance and data robustness. Details on the included indicators, their sources and their weighting are given in Supplementary 2.

\subsection{Data analysis: cluster analysis and spatial coefficients}

We undertook a cluster analysis to detect cities with similar levels of adaptation readiness. Milman et al. (2013) and Tilleard and Ford (2016) demonstrated that hierarchical clustering is suitable for grouping administrative units (in their case, international river catchments) that were assessed by different adaptation readiness factors. Since we aimed to identify cities with similar levels of adaptation readiness, we chose two algorithms that are particularly known for revealing homogeneous clusters: the Ward method and the Complete Linkage algorithm. We used the scores of the five factors of adaptation readiness (Fig. 1), i.e. (1) political leadership, (2) institutional organization, (3) adaptation decisionmaking, (4) availability of usable science and (5) implemented measures, as input variables and calculated the squared Euclidian distance to measure the distance between cities and clusters.

To choose a meaningful number of clusters we considered the following criteria:

- There were considerable changes in the overall similarity/distance measures when adding a new cluster.

- Similar clusters were detected with both of the methods applied (robustness).

- Kruskal-Wallis tests confirmed significantly different means per factor across the clusters.

- There were no or only small overlaps between the clusters with regard to the scores of the adaptation readiness index. 
On this basis, we chose the 2-cluster and 5-cluster solutions. Clusters were characterized by their cluster centres, i.e. the average score per factor considering all cities within a cluster, as well as the average adaptation readiness index and the average number of inhabitants of all cities within that cluster.

To further characterize the clusters and explore patterns of adaptation readiness, we adapted three spatial coefficients originating from economic geography (de Lange and Nipper 2018) to this study, i.e. the location quotient (LQ), the geographic concentration (GC) and the diversification index $\left(\mathrm{DIV}_{\mathrm{i}}\right)$. Calculation details are provided in Supplementary 3.

The LQ highlights local peculiarities of adaptation readiness (AR), i.e. how much each factor contributes to the AR index for a particular city in comparison to its contribution in the total data set. Values $<1$ indicate that the contribution of that factor is below average; values $>1$ indicate a contribution above average. In the results section, the average LQ per factor is also provided per cluster.

The GC determines how much one factor is concentrated in certain cities. In this paper, we used the coefficient to evaluate whether certain factors are so specific for certain cities that they could be neglected in the assessment of adaptation readiness.

The DIV measures how much each factor contributes to the adaptation readiness index for each city, assuming an equal contribution of each of the five factors as a reference. If the coefficient is closer to zero, this implies that the five factors are evaluated more or less equally in a city, while higher values of DIV indicate that a city tends to focus on one or two factors of adaptation readiness. Hence, the DIV coefficient is used to characterize cities' adaptation strategies.

\section{Results}

\subsection{Existence of climate adaptation plans}

As mentioned in the introduction, the literature comparing a large number of cities often uses the existence of climate adaptation plans as a single indicator to evaluate the state of adaptation (e.g. Reckien et al. 2014; 2018). Our results show that by the end of 2018, 61 out of 104 (59\%) cities had published an adaptation plan, and plans for a further 14 cities $(13 \%)$ were either in progress or in preparation (see Fig. 2). Based on our analysis, 29 (28\%) cities did not have an adaptation plan, nor were they preparing to develop one.

The first urban adaptation plan was published in 2007, and there was a marked increase in 2012. The year in which a city first published an adaptation plan and the content of the most current plan were considered as two of the 12 indicators within our adaptation readiness approach (see Fig. 1).

\subsection{City clusters of adaptation readiness}

Using the scores of the five factors that constitute the adaptation readiness index (Fig. 1) as inputs for the cluster analyses, both algorithms clearly resulted in a basic separation of the 104 cities into two groups of similar size. Figure 3 depicts the main characteristics of these clusters, i.e. their mean score per factor, together with the average adaptation readiness index and the mean number of inhabitants within the cities that belong to the same cluster. It reveals that we have one group of 'active cities': Cluster I, for which the Ward method identifies 50 cities with an average AR-index of 46.2 (minimum: 26.8, maximum: 66.7), 


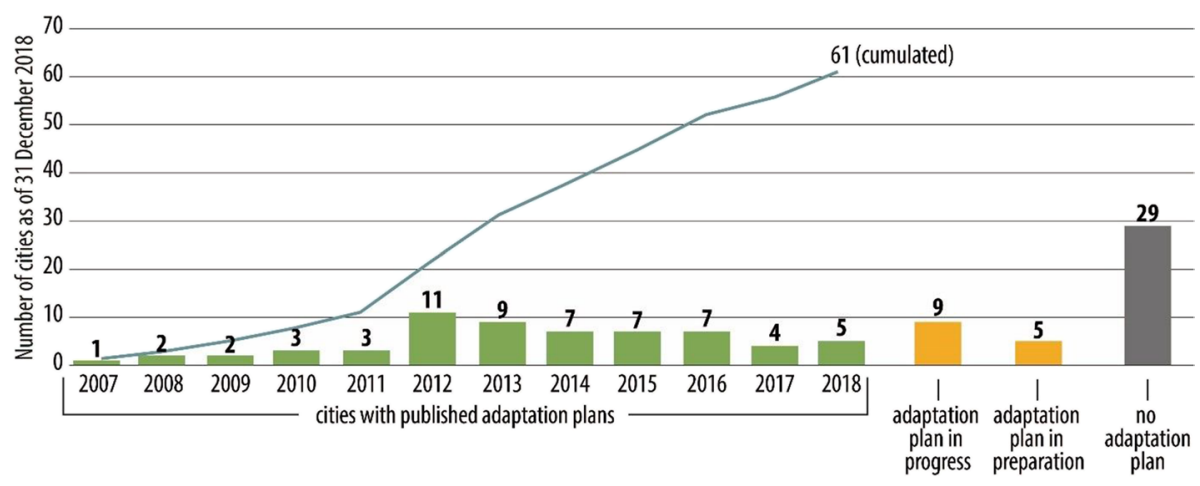

Fig. 2 Publication of adaptation plans per year (as of 31 Dec. 2018; for information on the search strategy, see Supplementary 2)

and for which the complete linkage algorithm identifies 47 cities showing an average ARindex of 46.4 (minimum: 26.8, maximum: 66.7). Our second group adopt a more 'waitand-see' approach: Cluster II comprises 54 cities according to the Ward method, which show a mean AR-index of 16.4 (minimum: 0, maximum: 40.2), whereas the complete linkage algorithm places 57 cities into this cluster, which have an average AR-index of 17.7 (minimum: 0, maximum: 43), see Fig. 3). Only five cities were classified differently by the two clustering algorithms, all of them having a score of around 40 points for the adaptation readiness index, which is at the upper range of the AR-index values in cluster II. Active cities (Cluster I) score - on average- higher on all five factors than cities of the wait-and-see group (Cluster II), but particularly highly with regard to the availability of adaptation plans as a basis for decision-making and the implementation of adaptation measures (Fig. 3). For these two factors, their average score exceeds 10 points, which is half of the potential maximum per factor (see Fig. 1).

When further dividing these initial two clusters, different adaptation strategies or pathways appear. Figure 4 shows that the two cluster approaches reveal similar patterns with five clusters. This classification differs clearly from the 4-cluster solution, while a sixth cluster does not add much new information (data not shown). The initial group of active cities (Cluster I in Fig. 3) is divided into three subgroups: While the first group (Cluster Ia), which achieves the highest average total score on the adaptation readiness index, is characterized by particularly high scores for political leadership, decision-making, usable science and implemented adaptation measures, the other two groups of active cities score high either with regard to decision-making and usable science (Cluster Ib) or with regard to the institutional organization of climate adaptation and implemented adaptation measures (Cluster Ic).

Within the initial wait-and-see group, a considerable number of cities (in Cluster IIa) are becoming increasingly active. This is reflected by higher mean scores for decisionmaking and institutional organization of climate adaptation (Fig. 4). In contrast, cities in Cluster IIb clearly underperform.

In Figs. 3 and 4, the average number of inhabitants as of December 2017 per cluster is depicted on the second y-axis. Clearly, the decreasing mean AR-index per cluster corresponds to a decreasing average number of inhabitants, revealing that more active cities are in general larger. This implies that bigger cities tend to be more ready for adaptation than 

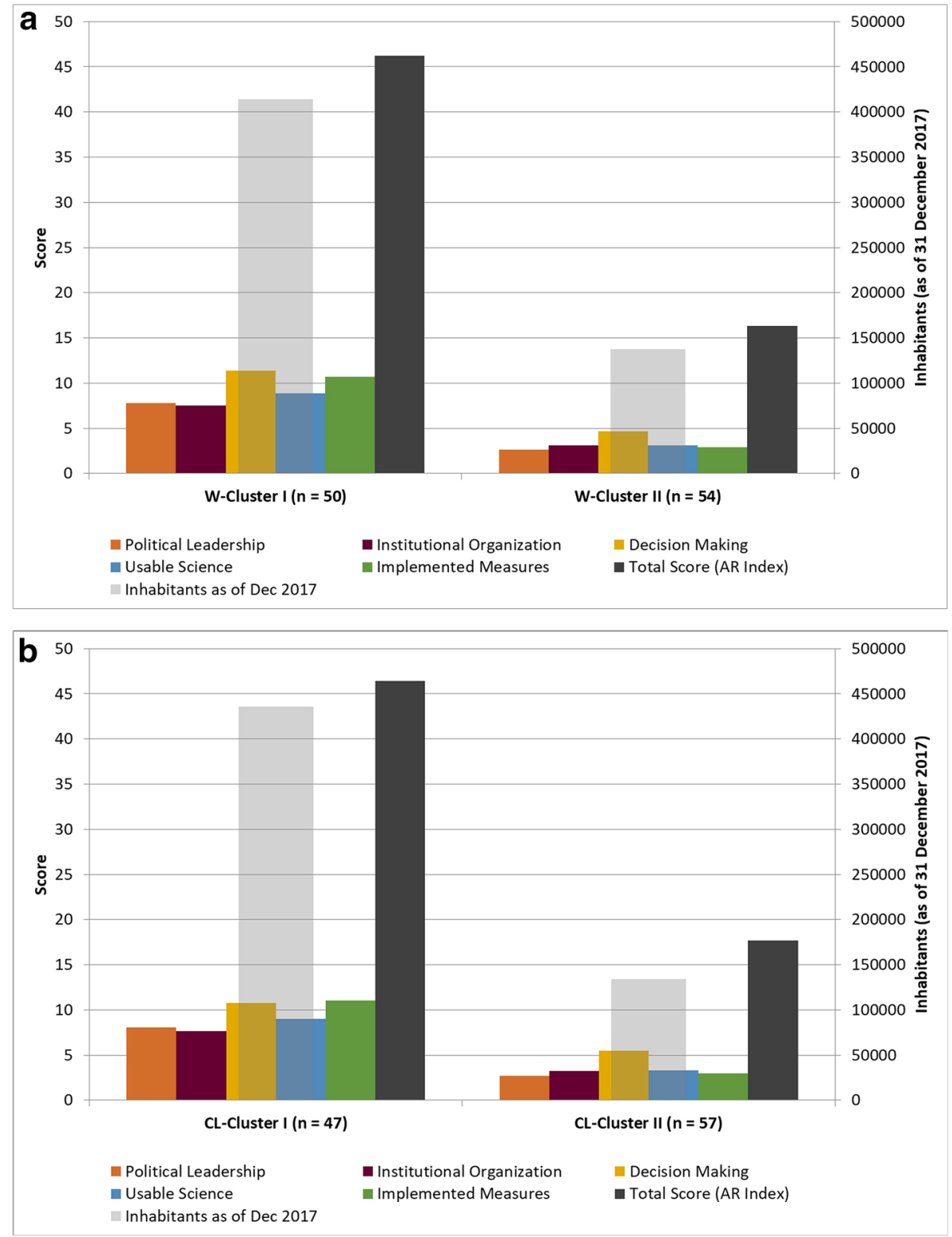

Fig. 3 Characterization of the 2-cluster solution according to the Ward-algorithm (W, top) and the Complete Linkage method (CL, bottom) using the five factors of adaptation readiness (AR) as input

smaller cities. Figure 4 also reveals that smaller cities might implement different strategies with regard to climate change adaptation, since the average numbers of inhabitants in Clusters Ib, Ic and IIa are rather similar (Fig. 4).

Spatial coefficients, particularly the location quotient LQ and the diversification index DIV, are used to further characterize the clusters. With regard to the 2-cluster solution, 

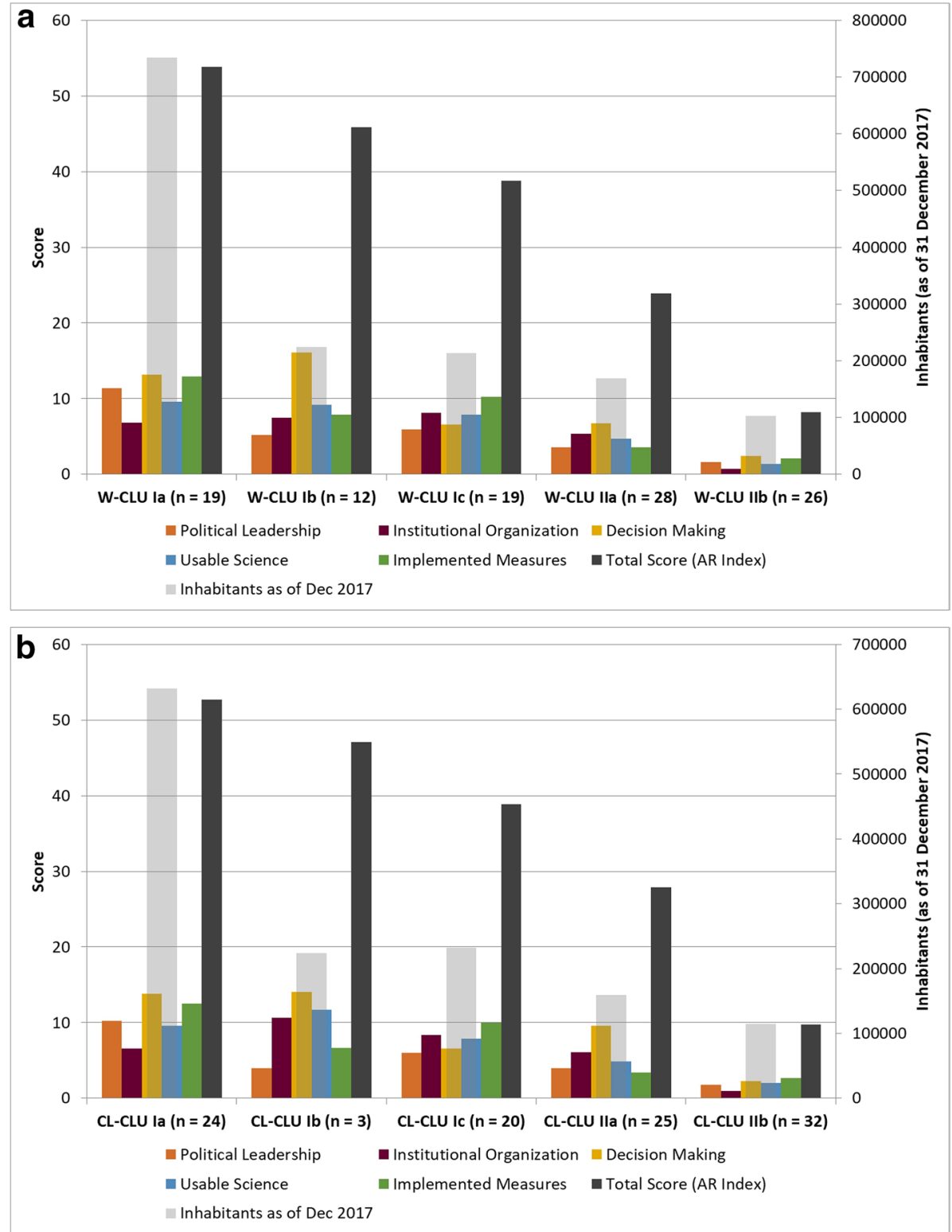

Fig. 4 Characterization of the 5-cluster solution according to the ward algorithm (W-CLU, top) and the complete linkage method (CL-CLU, bottom) using the five factors of adaptation readiness (AR) as input

Table 2 reveals that the LQ of most of the five factors is around 1. However, implemented adaptation measures contribute at an above-average level to the adaptation readiness of cities in Cluster I ( $\mathrm{LQ}=1.08$, see Table 2$)$ and at a below-average level for cities in Cluster II $(\mathrm{LQ}=0.9$, see Table 2). In cities of Cluster II, political leadership tends to play an important role. The DIV further reveals that the five factors of adaptation readiness are far more 
Table 2 Location quotients per factor of adaptation readiness and the diversification index in the clusters derived by the Ward method (see Fig. 4)

\begin{tabular}{lllllll}
\hline Cluster solution & \multicolumn{2}{l}{ Location quotient (LQ) } & & $\begin{array}{l}\text { Diversi- } \\
\text { fication } \\
\text { 2 Clusters (Ward) }\end{array}$ \\
\cline { 2 - 6 } & $\begin{array}{l}\text { Political } \\
\text { leader- } \\
\text { ship }\end{array}$ & $\begin{array}{l}\text { Institutional } \\
\text { organization }\end{array}$ & Decision-making & Usable science & $\begin{array}{l}\text { Imple- } \\
\text { mented } \\
\text { measures }\end{array}$ & \\
\hline Cluster I & 0.98 & 0.97 & 0.94 & 1.03 & 1.08 & 0.19 \\
Cluster II & 1.20 & 0.92 & 1.05 & 0.95 & 0.90 & 0.42 \\
5 Clusters (Ward) & & & & & & \\
Cluster Ia & 1.27 & 0.74 & 0.95 & 0.93 & 1.11 & 0.15 \\
Cluster Ib & 0.68 & 0.96 & 1.38 & 1.05 & 0.78 & 0.24 \\
Cluster Ic & 0.88 & 1.21 & 0.66 & 1.11 & 1.23 & 0.21 \\
Cluster IIa & 0.89 & 1.26 & 1.03 & 1.10 & 0.75 & 0.28 \\
Cluster IIb & 1.57 & 0.51 & 1.07 & 0.76 & 1.08 & 0.59 \\
\hline
\end{tabular}

balanced in cities of Cluster I than in cities of Cluster II (DIV $=0.19$ versus DIV $=0.42$ see Table 2), underlining that cities of Cluster I are more advanced with respect to adaptation readiness as a whole.

The DIV also helps to rank the clusters of the 5-cluster solution. Cities in Cluster Ia can be regarded as very active/pioneering cities, since they are advanced with respect to all five factors of adaptation readiness (DIV $=0.15$, Table 2). On the other hand, cities of Cluster IIb produce the highest diversification index (DIV $=0.59$, Table 2) illustrating that these cities show single activities with regard to just a few factors of adaptation readiness, while others are neglected. Cities in Clusters Ib, Ic and IIa are in the middle. It should be noted that cities of Clusters Ib are strong in institutional organization and strategic decision-making, whereas those in Ic perform well in institutional organization and the implementation of adaptive measures (Fig. 4, Table 2). Hence, they should be regarded as actively adapting cities.

The cluster analyses and spatial coefficients illustrate that adaptation is a complex and heterogeneous field. Therefore, different dimensions or factors should be considered when evaluating and monitoring adaptation. This is supported by the index of geographic concentration GC: all five factors result in index values that differ markedly from zero (they range between 0.15 and 0.21 ; data not shown). Therefore, to track adaptation readiness in the future, studies should seek to measure all of these different factors.

\subsection{Typology of adaptation readiness}

Based on the adaptation readiness index and the results of the cluster analyses, we ranked the 104 cities and further divided them into four groups characterizing their level of climate adaptation: (1) pioneering cities, (2) active cities, (3) less active cities and (4) waiting cities (Table 3). This classification is not based on an equal distance between the index scores (e.g. a new group starts every 10 points) but aims to combine cities with similar scores and separate groups at irregularities and cluster boundaries (Fig. 5).

The cities achieved a broad range of adaptation readiness index scores: three did not receive any points, whereas the city with the highest score (Bremen) acquired 67 out of 100 points. Cities with a high score are assumed to be better prepared for adapting to climate 


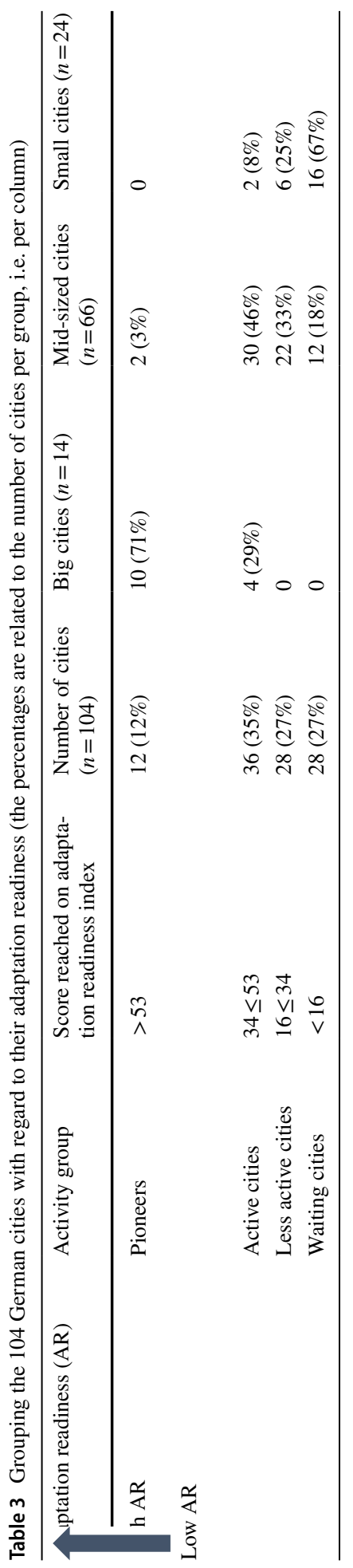




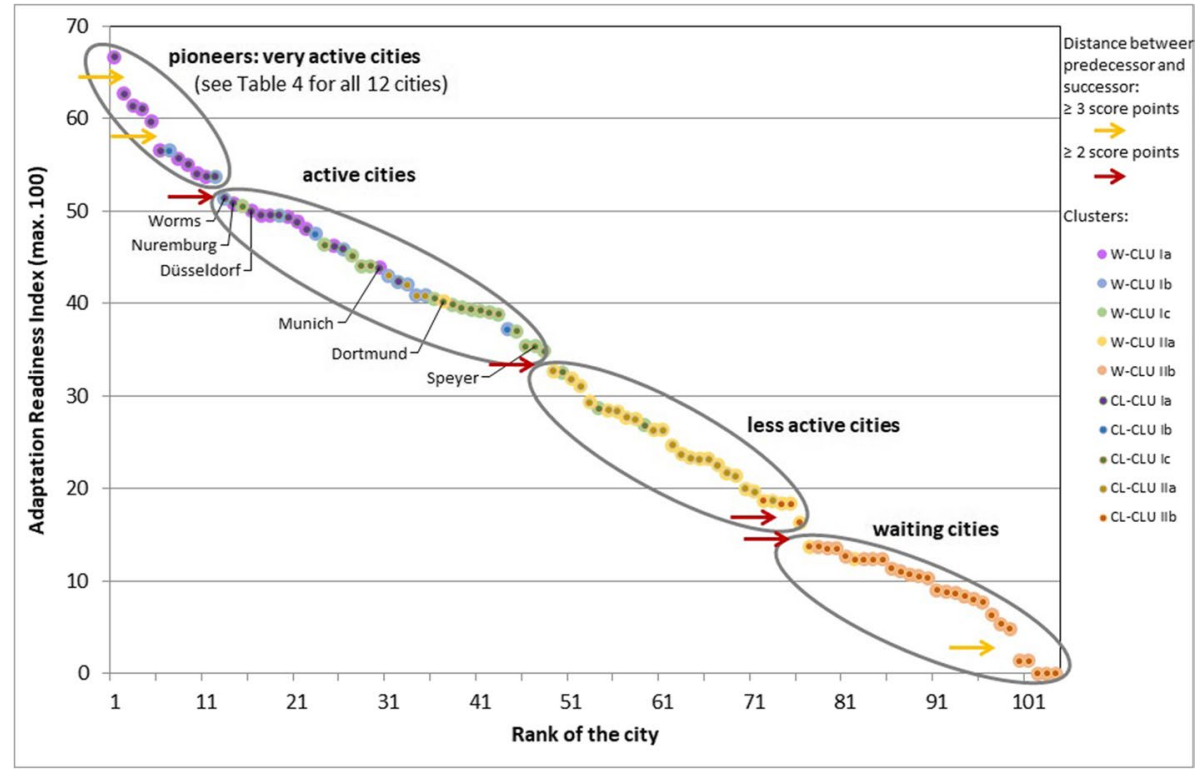

Fig. 5 Distribution of all 104 German cities concerning their adaptation readiness (Some cities mentioned in the text are shown in the figure. A detailed list of all cities can be found in Supplementary 1)

change or 'readier' to cope with climate change impacts, e.g. extreme weather events. As Fig. 5 shows, cities space out evenly within the range of 0-67. There are only three places at which cities are separated by more than three points; these are located either at the upper or lower scoring end. Next to this, three further cities achieved at least two points more than the following city. Together with the 5-cluster solutions, these breakpoints were used to separate the activity groups (see Fig. 5).

The twelve pioneer cities are listed with their scores and further characteristics in Table 4, and a detailed list of all cities can be found in Supplementary 1. These lists show that ten out of the twelve pioneers are big cities with more than 500,000 inhabitants. This is remarkable, since there are only 14 big cities in Germany in total. Hence, around $70 \%$ of big cities were grouped as pioneers, and the remaining four (Nuremberg, Düsseldorf, Munich and Dortmund) are all classified as 'active'. Just two medium-sized cities (i.e. 3\% of 66), i.e. Potsdam and Karlsruhe, can be found in the pioneering group (Table 4). However, 30 of these cities (i.e. $45 \%$ ) are active, while a third (22) were considered less active and 12 (i.e. 18\%) as waiting. So, around half of the medium-sized cities are (very) active. This distribution changes considerably when the 24 small independent cities are analysed. There is no small city in the pioneering group and just two (8\%) in the group of active cities, namely, Worms and Speyer. A quarter of the small cities (i.e. 6) were found to be less active, while two thirds (16 cities) were classified as waiting cities.

To further analyse the role of city size on adaptation readiness, we performed a correlation analysis that revealed a medium, though significant, correlation between the number of inhabitants and the adaptation readiness index $(r=0.463 ; p=0.01)$. Figure 6 illustrates this relation with a non-linear regression that explains $46 \%$ of the data variance. If we exclude 
Table 4 Overview of cities pioneering in adaptation readiness in Germany

\begin{tabular}{llllll}
\hline City name & $\begin{array}{l}\text { Ranking } \\
\text { number }\end{array}$ & $\begin{array}{l}\text { Inhabitants (as } \\
\text { of 31 Dec. 2017) }\end{array}$ & Type of city size & $\begin{array}{l}\text { Score of adapta- } \\
\text { tion readiness } \\
\text { index }\end{array}$ & $\begin{array}{l}\text { Cluster in the } \\
\text { 5-cluster solu- } \\
\text { tion } \\
\text { (Ward // Com- } \\
\text { plete Linkage) }\end{array}$ \\
\hline Bremen & 1 & 568,006 & Big city & Ia // Ia \\
Cologne & 2 & $1,080,394$ & Big city & 66.67 & Ia // Ia \\
Frankfurt (Main) & 3 & 746,878 & Big city & 62.67 & Ia // Ia \\
Hamburg & 4 & $1,830,584$ & Big city & 61.33 & Ia // Ia \\
Berlin & 5 & $3,613,495$ & Big city & 61.00 & Ia // Ia \\
Dresden & 6 & 551,072 & Big city & 59.67 & $\mathrm{Ia} \mathrm{//} \mathrm{Ia}$ \\
Potsdam & 6 & 175,710 & Medium-sized city & 56.50 & $\mathrm{Ib} / / \mathrm{Ib}$ \\
Karlsruhe & 7 & 311,919 & Medium-sized city & 55.67 & $\mathrm{Ia} / / \mathrm{Ia}$ \\
Stuttgart & 8 & 632,743 & Big city & 55.00 & $\mathrm{Ia} / / \mathrm{Ia}$ \\
Hanover & 9 & 535,061 & Big city & 54.00 & $\mathrm{Ia} / / \mathrm{Ia}$ \\
Essen & 10 & 583,393 & Big city & 53.67 & $\mathrm{Ia} / / \mathrm{Ia}$ \\
Leipzig & 10 & 581,980 & Big city & 53.67 & $\mathrm{Ib} / / \mathrm{Ia}$ \\
\hline
\end{tabular}

Berlin from the city sample, as it is by far the biggest city in Germany, ${ }^{3}$ the correlation coefficient increases $(r=0.544 ; p=0.01)$.

\section{Discussion}

The results show that 61 out of 104 cities have an adaptation plan; with a few exceptions, most of these were published in 2012 or later (Fig. 2). This coincides with the publication of the German (National) Action Plan for Adaptation and the initiation of a federal funding scheme to develop local adaptation plans. Compared internationally, this seems rather early as Olazabal and Ruiz De Gopegui (2021) found that most of the adaptation plans of 59 big coastal cities were published after 2015. Taking a closer look at Germany, studies have come to quite different results: findings on the existence of adaptation plans in cities range from 18\% (Hasse and Willen 2019) to 25\% (Reckien et al. 2018) to 64\% (Kind and Sartison 2017). Our results even exceed these numbers: by the end of 2018, 59\% of cities had already published plans and $13 \%$ were in the process of establishing one or had taken initial steps toward preparing one. One major reason for this variation is the differing city sample, as city size is a major influencing factor in the existence of adaptation plans (Araos et al. 2016; Reckien et al. 2018; see also Fig. 6). Another aspect is that climate adaptation is becoming an increasingly popular policy field (Fig. 2), so that analyses conducted just a few years ago might yield different results and conclusions than more recent studies.

\footnotetext{
${ }^{3}$ Berlin has about 3.6 million inhabitants, which is twice as much as Hamburg-the second biggest city in Germany (https://www.destatis.de/DE/ZahlenFakten/LaenderRegionen/Regionales/Gemeindeverzeichnis/ Administrativ/Aktuell/05Staedte.html).
} 


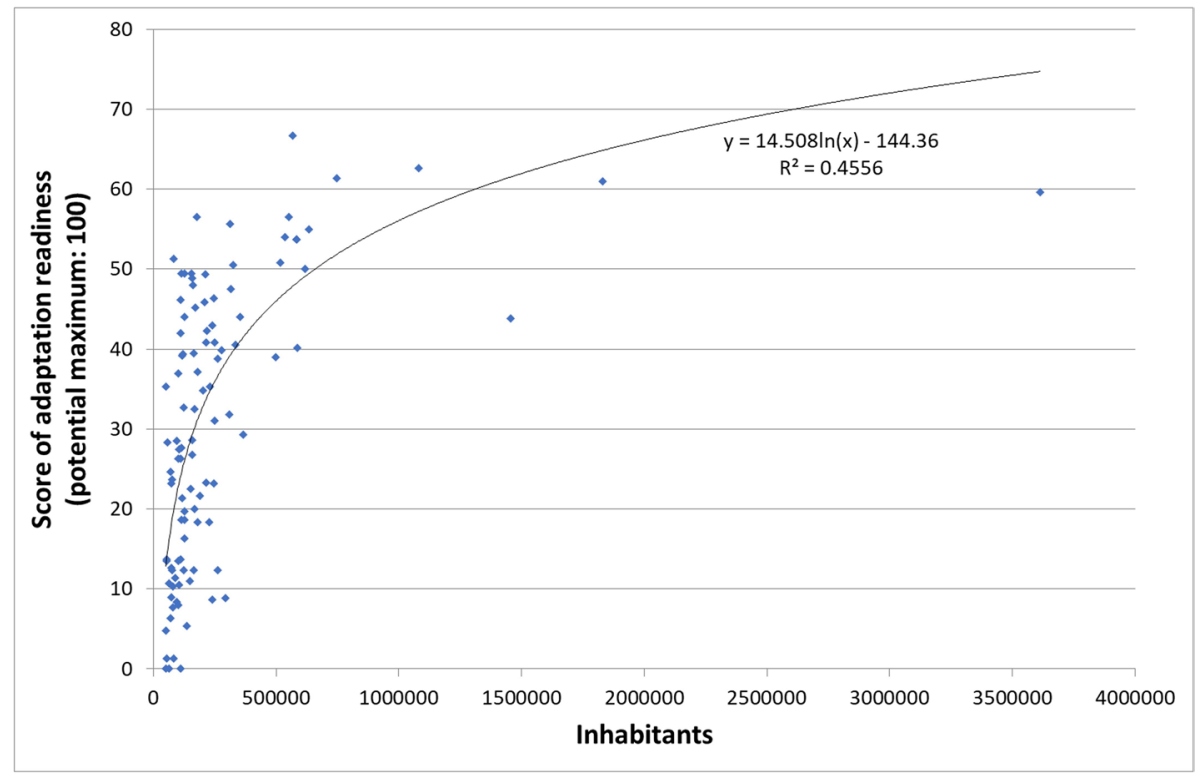

Fig. 6 Relation between the number of inhabitants (as of 31 December 2017) and the score on the adaptation readiness index per city $(n=104)$. (A detailed list of all cities can be found in Supplementary 1 )

This paper provides a more complex picture of adaptation processes than the literature so far, including how it is progressing in different-sized cities and examining various factors and indicators on adaptation preparedness. Our results show, for example, that three cities without any published plan are nonetheless still 'active', whereas a further 14 that have not published a plan are grouped as 'less active.' Nine out of these 17 cities are planning to establish a concept or are already developing one. These cities are mostly found in Cluster Ic, which shows comparably high scores on implementation but less in terms of adaptation decision-making (Figs. 3 and 4). This implies that a sole focus on the existence of adaptation plans runs the risk of overlooking implemented adaptation activities.

In general, the findings of the cluster analysis revealed that there is not just one way of adapting to climate change, but instead cities show different degrees of focus on the five factors of adaptation readiness, which are themselves partly interrelated with different phases within the adaptation progress (Fig. 5). Very active cities (12 cities, Table 4) tend to show considerable contributions to all five factors are largely in Cluster Ia in Fig. 4, while active cities (36) are particularly diverse in their focus on specific factors (mostly Clusters $\mathrm{Ib}$, Ic and IIa). A closer look reveals that cities in cluster Ib score very high on decisionmaking (Fig. 4), as their adaptation plans contain a huge range of measures. Indeed, adaptation in these cities might be characterized as 'strategic management'. Cities in cluster Ic, in contrast, score comparatively highly on implementation and institutional organisation of adaptation and could be summarized as 'cities of (institutionalized) adaptation action', even though their adaptation plans are either not very detailed or still in preparation. The distribution of the mean factor scores of cities in cluster IIa is similar to those in cluster Ib (Fig. 4), but scores are at a lower level. This suggests that these cities are lagging behind but benefit from good practice examples. Finally, less active cities (28) as well as waiting cities (28) score (very) low on all factors (mostly Cluster IIa and particularly IIb). 
Concerning the question of how active cities are and whether they are able to meet high expectations regarding their climate actions (Castán Broto and Westman 2020; Van der Heijden 2019), our results provide additional insights. We show that a small group of cities (12) are already taking broad actions to adapt to climate change and about a third of the investigated cities are taking some actions. Despite this activity, however, even the highestscoring cities reached just two thirds of all potential points and thus there may be room for improvement in some aspects of preparedness, especially institutional organisation and usable science. More pilot projects with participatory research approaches could also foster adaptation on the local level. Additionally, around half of the 104 cities are grouped less active or not active at all, with $41 \%$ of the cities not having an adaptation plan by the end of 2018 (although some were in the pipeline) and, according to our data, 22\% of cities implementing nothing. Thus our study underlines, that city preparedness for adaptation is very diverse (see Fig. 5). We suggest that-despite a few leading cities and various actions already taken-many German cities still have some way to go before they are well prepared for climate change and more action is needed, especially for adaptation in mid-sized and smaller cities (Fig. 6).

Indeed, our results also add further insights to the knowledge (e.g. Reckien et al. 2015; Hackenbruch et al. 2017; Salvia et al. 2021) that the size of a city is an important factor in the climate policy actions taken (in our data see Fig. 6). Big cities are all either pioneers (Table 4 ) or very active and small cities are mostly waiting or less active (Table 3). Scaling effects of city size have frequently been detected in urban studies, e.g. with regard to the urbanized area, employment, the number of patents or the gross domestic product (Bettencourt and Lobo 2016). The fact that average incomes tend to be higher in big cities and that they have better access to (inter-)national services, trickles down to other policy fields, such as sustainable development (Brelsford et al. 2017). Our results suggest that similar factors are in play with climate adaptation. Even with the same per-capita tax income and the same share dedicated to adaptation, a bigger city could employ more personnel in this policy field than a smaller city. Consequently, a bigger city is able to hire more specialized and probably better trained staff.

However, results are less conclusive regarding the group of medium-sized cities: they can be found in every activity group and various clusters. Based on the ranking approach, we can also detect medium-sized and small cities which are more active than most of the other cities in their peer group. The mid-sized cities Potsdam and Karlsruhe are the only ones ranked as pioneers, and the small cities Speyer and Worms are the only ones grouped as active cities within their respective city size group. The cities of Karlsruhe, Speyer and Worms might all already feel a sense of urgency as they are highly exposed to heat due to their location in the warmest region in Germany (the Upper Rhine Drift). Potsdam benefits from a range of locally based scientific institutions, such as the Potsdam Institute for Climate Impact Research (Kern et al. 2018). Furthermore, strong local political engagement for adaptation can be found in all four of these cities (see e.g. Kind et al. (2014) for a study of Speyer and Kern et al. (2018) for Potsdam) and they have successfully applied for funding for adaptation projects. These cities can act as role models within their respective city size group, as literature (Dulal 2019; Van der Heijden 2019) points out that emulating big cities might be out of scope for many medium-sized and small municipalities due to diverse conditions. Smaller and mid-sized cities seem to be in particular need of support in order to take (initial) actions (Hasse and Willen 2019), but even some big cities may only be able to take actions with the help of external funding. To take urban adaptation further, we therefore recommend that policymakers provide broad funding opportunities to help cities develop adaptation plans, hire experienced personnel, implement measures and 
strengthen knowledge exchange possibilities and that such initiatives should be tailored to smaller cities.

Contributing to the literature on adaptation readiness, our analysis exemplifies how we can analyse the activities of a large number of cities using online resources. Although conducting the research into 'implemented measures' and other indicators was quite time-consuming, the cluster analyses and spatial coefficients indicate that each of the five factors is important in itself; one cannot substitute the other, since cities score quite differently across each of them. In line with the experiences of Tilleard and Ford (2016) and Ford and King (2015), we were not able to include the factors of 'finances' and 'public support' due to a lack of (accessible) data (see Supplementary 2 for details). Future works could examine how these factors might be included in the analysis and, in smaller samples, investigate their overall impact on the ranking results. Indeed, Olazabal and Ruiz De Gopegui's (2021) investigation of big coastal cities uses budget information contained in adaptation plans as an indicator of 'finance' and survey data into public concerns regarding climate change to measure 'public support'. However, survey data was not available for the cities investigated in our sample. Another limitation of our study, which is common within the literature on adaptation tracking (Ford et al. 2013; Aguiar et al. 2018; Klostermann et al. 2018), is that we only considered actions that were clearly framed as climate adaptation and might have missed relevant initiatives that were implemented without the use of this specific jargon. ${ }^{4}$ Future studies could try to overcome this problem by defining measures that are crucial for comprehensive adaptation, search directly for these measures and include them in the analysis, e.g. in the factor 'implementation'. However, the work involved in identifying which terms and measures might be relevant and applied consistently across different cities could be substantial and possibly not worth undertaking on a large scale.

Our analysis considers the aspect of time within the factor of 'institutional organization' so that early adaptors score higher on this factor; however, the study cannot retrace dynamic processes in detail. Climate adaptation in cities presents a dynamic process that does not have to follow a linear path from 'no adaptation' to 'ideal adaptation'. Instead, cities might act early on climate adaptation but limit their engagements later on, owing to resource limitations or changes in political support (Eisenack et al. 2014). Conversely, cities might become active very late but invest a lot of resources into the area and implement measures rapidly. In order to react to new findings and urban changes and to monitor the process of implementation, updating adaptation plans in a 6-year cycle (as foreseen in other European policies, such as the Flood Directive and the Water Framework Directive), as part of a process that is supported by funding programmes, could help to ensure that cities keep on top of the situation.

Our study extended the factors of adaptation readiness by considering 'implemented measures' as an additional factor and thus goes beyond the planning phase. Retrieving suitable data was possible because most city councils in Germany publish all meeting documents in online-accessible council information systems. Such a valuable source of information might not be available or accessible in other countries. Despite the insight this factor gives, we do not consider whether planned or implemented measures and actions in certain cities are reasonable or might be successful, since this question can be better answered by detailed case studies. However, an analysis of the measures mentioned in 61

\footnotetext{
${ }^{4}$ In this study, we do not include measures on flood protection from river floods, since in Germany the federal states and not the cities are responsible for riverine flood protection measures. This is in line with analyses in Italy, Spain and the Netherlands (Heidrich et al. 2016).
} 
published adaptation plans indicates that health issues and related actions have not yet been sufficiently considered (Thieken et al. 2018).

\section{Conclusion}

In this paper, we analysed the adaptation readiness of 104 German cities in terms of five factors with twelve indicators, clustered them depending on the contribution of these factors to the overall adaptation readiness index and grouped them according to their total score and cluster affiliations. In the end, we distinguished four groups of cities. The pioneering dozen showed comparatively high scores for all five factors of adaptation readiness. This group mainly contains big cities with more than 500,000 inhabitants. These are followed by a larger group of 36 cities that are actively engaged in climate adaptation, but which follow different strategies. A further 28 cities are less active, while another 28 , particularly small cities, scored the lowest and must be considered as cities that still 'wait and see'. Altogether, our analysis provides insights into which German cities are already (very) active and which are lagging behind, as well as in which action fields certain cities show quite good results and in which little has been achieved so far. We assess that, overall, (much) more action on preparing (and implementing) urban adaptation is needed.

These insights can inform decision-making, as politicians and other engaged actors on the ground can draw general or city-specific conclusions regarding, e.g. future support and resource distributions. This is mainly relevant for higher tiers of government, such as the state or even federal level, which are much better placed to provide funding and support. Climate adaptation is just one of many challenges cities face. Therefore extended, easily accessible and long-term funding seems necessary for many cities to become or stay active. This seems to be particularly important for medium-sized cities and small cities, since 52\% and $92 \%$ of them, respectively, were identified as less active or waiting cities.

The study responds to shortcomings some studies encounter when they only consider adaptation plans to track climate adaptation (e.g. Reckien et al. 2014; 2018; Heidrich et al. 2013; Olazabal et al. 2014), and it represents a novel large-N study into adaptation readiness (Ford et al. 2013). Regarding the concept and method of adaptation readiness, future studies need to figure out how to measure the factors 'finances' and 'public support' (which we found difficult to furnish with data) and whether any common indicators could be used in transnational comparisons for which relevant data are straightforward to collect.

Regarding the results, there are various aspects future research could address. First, studies could investigate which aspects (e.g. exposure, socio-economic characteristics, political situation) influence adaptation actions beyond the factor of city size and how these results relate to findings from other studies (e.g. Reckien et al. 2015; Shi et al. 2015). Second, our results could be validated through detailed case studies of a few of the 104 cities or by surveying the perceptions of pioneering cities and professionals working in the field of urban climate adaptation. This would respond to the lack of validation of adaptation readiness analyses and their results (Ford et al. 2013). Third, in replicating the analysis in a few years' time, or after important changes in regulations, and by using our results as a baseline, future studies could investigate how adaptation readiness develops over time, search for different trends among the cities and for explanations, and assess the effects of governance changes. Fourth, there is a lack of knowledge on how-if at all-the extent of cities' actions in the field of climate mitigation and climate adaptation are related to each other, e.g. whether or not mitigation pioneers are also forerunners in climate adaptation and 
why. Since all 104 cities studied in this paper have already published mitigation plans, such an analysis needs to focus on several other indicators. Fifth, comparing our data with the adaptation readiness of cities in other countries that have an obligatory system of developing municipal adaptation plans could lead to insights on whether and how the legal context within which adaptation plans are developed influences cities' activities. Such a study might examine whether mandating climate adaptation activity within municipalities affects the way in which cities are responding to the issue.

Although there is still a lot to investigate, we nonetheless argue that the adaptation readiness approach is applicable to a large number of cities and that it reflects the complexity of climate adaptation by revealing the peculiarities of different realities on the ground.

Supplementary Information The online version contains supplementary material available at https://doi. org/10.1007/s11027-021-09971-4.

Acknowledgements The authors would like to thank Julia Dierck, Alice Künzel, Philipp Schneider and Ariane Walz for supporting this study by researching and providing data for some of the indicators as well as Peter Eckersley and two anonymous reviewers for their comments and suggestions.

Funding Open Access funding enabled and organized by Projekt DEAL. This study was developed within the framework of the joint research project "Urban resilience against extreme weather events-typologies and transfer of adaptation strategies in small metropolises and medium-sized cities" (ExTrass) funded by Germany's Federal Ministry of Education and Research (BMBF, FKZ 01LR1709A1).

\section{Declarations}

Conflict of interest The authors declare that they have no conflict of interest.

Open Access This article is licensed under a Creative Commons Attribution 4.0 International License, which permits use, sharing, adaptation, distribution and reproduction in any medium or format, as long as you give appropriate credit to the original author(s) and the source, provide a link to the Creative Commons licence, and indicate if changes were made. The images or other third party material in this article are included in the article's Creative Commons licence, unless indicated otherwise in a credit line to the material. If material is not included in the article's Creative Commons licence and your intended use is not permitted by statutory regulation or exceeds the permitted use, you will need to obtain permission directly from the copyright holder. To view a copy of this licence, visit http://creativecommons.org/licenses/by/4.0/.

\section{References}

Aguiar FC, Bentz J, Silva JMN, Fonseca AL, Swart R, Santos FD, Penha-Lopes G (2018) Adaptation to climate change at local level in Europe: an overview. Environ Sci Policy 86:38-63. https://doi.org/10. 1016/j.envsci.2018.04.010

Alber G, Kern K (2008) Governing climate change in cities: modes of urban climate governance in mulitlevel systems. Paper Presented at the OECD International Conference, Competitive Cities and Climate Change, 2nd Annual Meeting of the OECD Roundtable Strategy for Urban Development

Araos M, Berrang-ford L, Ford JD, Austin SE, Biesbroek R, Lesnikowski A (2016) Climate change adaptation planning in large cities: a systematic global assessment. Environ Sci Policy 66:375-382. https:// doi.org/10.1016/j.envsci.2016.06.009

Araos M, Ford J, Berrang-Ford B, Biesbroek R, Moser S (2017) Climate change adaptation planning for Global South megacities: the case of Dhaka. J Environ Planning Policy Manage 19(6):682-696. https://doi.org/10.1080/1523908X.2016.1264873

Bausch T, Koziol K (2020) New policy approaches for increasing response to climate change in small rural municipalities. Sustainability 12(6):17. https://doi.org/10.3390/su12051894

Berrang-Ford L, Biesbroek R, Ford JD, Lesnikowski A, Tanabe A, Wang FM, Chen C, Hsu A, Hellmann JJ, Pringle P, Martina Grecequet JC, Amado SH, Shuaib Lwasa S, Heymann J (2019) Tracking global 
climate change adaptation among governments. Nat Clim Chang 9(6):440-449. https://doi.org/10. 1038/s41558-019-0490-0

Bettencourt Luís MA, Lobo J (2016) Urban scaling in Europe. J R Soc Interface 13:20160005. https://doi. org/10.1098/rsif.2016.0005

Biagini B, Bierbaum R, Stults M, Dobardzic S, McNeeley SM (2014) A typology of adaptation actions: A global look at climate adaptation actions financed through the Global Environment Facility. Glob Environ Chang 25(1):97-108. https://doi.org/10.1016/j.gloenvcha.2014.01.003

Biesbroek GR, Klostermann JEM, Termeer CJAM, Kabat P (2013) On the nature of barriers to climate change adaptation. Reg Environ Change 13(5):1119-1129. https://doi.org/10.1007/s10113-013-0421-y

Biesbroek R, Berrang-Ford L, Ford JD, Tanabe A, Austin SE, Lesnikowski A (2018) Data, concepts and methods for large-n comparative climate change adaptation policy research: a systematic literature review. Wires Clim Change 9:e548. https://doi.org/10.1002/wcc.548

Birkmann J, Welle T, Solecki W, Lwasa S, Garschagen M (2016) Boost resilience of small and mid-sized cities. Nature 537:605-608. https://doi.org/10.1038/537605a

Brelsford C, Lobo J, Handa J, Bettencourt LMA (2017) Heterogeneity and scale of sustainable development in cities. - PNAS 114(34): 8963-8968, www.pnas.org/cgi/doi/10.1073/pnas.1606033114

Brink E, Wamsler C (2019) Citizen engagement in climate adaptation surveyed: The role of values, worldviews, gender and place. J Clean Prod 209:1342-1353. https://doi.org/10.1016/j.jclepro.2018.10.164

Bulkeley H, Kern K (2006) Local government and the governing of climate change in Germany and the UK. Urban Studies 43(12):2237-2259. https://doi.org/10.1080/00420980600936491

Bundesinstitut für Bau-, Stadt und Raumforschung (BBSR) (2017) Laufende Stadtbeobachtung - Raumabgrenzungen https://www.bbsr.bund.de/BBSR/DE/Raumbeobachtung/Raumabgrenzungen/deutschland/ gemeinden/StadtGemeindetyp/StadtGemeindetyp_node.html. [last accessed 19 May 2020].

Cai H, Lam NSN, Qiang Yi, Zou L, Correll RM, Mihunov V (2018) A synthesis of disaster resilience measurement methods and indices. Int J Disas Risk Reduc 31:844-855. https://doi.org/10.1016/j.ijdrr.2018. 07.015

Carter JG, Cavan G, Connelly A, Guy S, Handley J (2015) Climate change and the city: Building capacity for urban adaptation. Prog Plan 95:1-66. https://doi.org/10.1016/j.progress.2013.08.001

Castán Broto, Vanesa, and Harriet Bulkeley. 2013 A survey of urban climate change experiments in 100 Cities. Global Environ Chang 23 (1): 92-102. https://doi.org/10.1016/j.gloenvcha.2012.07.005

Castán Broto V, Westman LK (2020) Ten years after Copenhagen: Reimagining climate change governance in urban areas. Wiley Interdisciplinary Reviews: Climate Change, 11(4), 1-22. https://doi.org/10.1002/ wcc. 643

Davoudi S, Crawford J, Mehmood A (2009) Planning for climate change: strategies for mitigation and adaptation for spatial planners. Earthscan

Coninck, Heleen de, Aromar Revi, Mustafa Babiker, Paolo Bertoldi, Marcos Buckeridge, Anton Cartwright, Wenjie Dong, et al. 2018. "Chapter 4 - Strengthening and Implementing the Global Response." In Global Warming of $1.5^{\circ} \mathrm{C}$. An IPCC Special Report on the Impacts of Global Warming of $1.5^{\circ} \mathrm{C}$ above Pre-Industrial Levels and Related Global Greenhouse Gas Emission Pathways, in the Context of Strengthening the Global Response to the Threat of Climate Change, edited by V. Masson-Delmotte, P. Zhai, H. O. Pörtner, D. Roberts, J. Skea, P. R. Shukla, A. Pirani, et al. https://www.ipcc.ch/site/assets/ uploads/sites/2/2019/05/SR15_Chapter4_Low_Res.pdf. [last accessed 19 May 2020].

Dhar TK, Khirfan L (2017) Climate change adaptation in the urban planning and design research: missing links and research agenda. J Environ Planning Manage 60(4):602-627. https://doi.org/10.1080/09640 568.2016 .1178107

Dulal HB (2019) Cities in Asia: how are they adapting to climate change? J Environ Stud Sci 9(1):13-24. https://doi.org/10.1007/s13412-018-0534-1

Eisenack K, Moser SC, Hoffmann E, Klein RJT, Oberlack C, Pechan A, Rotter M, Termeer CJAM (2014) Explaining and overcoming barriers to climate change adaptation. Nat Clim Chang 4(10):867-872. https://doi.org/10.1038/nclimate2350

Ellena, Marta, Margaretha Breil, and Stefano Soriani. 2020. The heat-health nexus in the urban context: A systematic literature review exploring the socio-economic vulnerabilities and built environment characteristics. Urban Clim, 34. https://doi.org/10.1016/j.uclim.2020.100676.

Engle NL (2011) Adaptive capacity and its assessment. Global Environ Chang 21 (2): 647-56. https://doi. org/10.1016/j.gloenvcha.2011.01.019

Ford JD, Berrang-Ford L (2016) The 4Cs of adaptation tracking: consistency, comparability, comprehensiveness, coherency. Mitig Adapt Strat Glob Change 21(6):839-859. https://doi.org/10.1007/ s11027-014-9627-7

Ford JD, King D (2015) A framework for examining adaptation readiness. Mitig Adapt Strat Glob Change 20:505-526. https://doi.org/10.1007/s11027-013-9505-8 
Ford JD, Berrang-Ford L, Lesnikowski AC (2013) How to track adaptation to climate change: a typology of approaches for national-level application. Ecol Soc 18(3):40. https://doi.org/10.5751/ES-05732-180340

Ford JD, Lea Berrang-Ford, Robbert Biesbroek, Malcolm Araos, S. E. Austin, and A. Lesnikowski (2015) Adaptation tracking for a post-2015 climate agreement. Nat Clim Chang 5 (11): 967-69. https://doi. org/10.1038/nclimate2744

Ford JD, Labbé J, Flynn M, Araos M (2017) Readiness for climate change adaptation in the arctic: a case study from Nunavut, Canada. Clim Change 145(1-2):85-100. https://doi.org/10.1007/ s10584-017-2071-4

Fuhr H, Hickmann T, Kern K (2018) The Role of cities in multi-level climate governance: Local Climate Policies and the $1.5{ }^{\circ} \mathrm{C}$ Target. Curr Opin Environ Sustain 30. https://doi.org/10.1016/j.cosust. 2017.10.006

Geneletti D, Zardo L (2016) Ecosystem-based adaptation in cities: An analysis of European urban climate adaptation plans. Land Use Policy 50:38-47. https://doi.org/10.1016/j.landusepol.2015.09. 003

Göpfert C, Wamsler C, Lang W (2019) Institutionalizing climate change mitigation and adaptation through city advisory committees: Lessons learned and policy futures. City Environ Interact, 1. https://doi.org/10.1016/j.cacint.2019.100004

Göpfert C, Wamsler C, Lang W (2020) Enhancing structures for joint climate change mitigation and adaptation action in city administrations - empirical insights and practical implications. City Environ Interact 8:100052. https://doi.org/10.1016/j.cacint.2020.100052

Hackenbruch J, Kunz-Plapp T, Müller S, Schipper JW (2017) Tailoring climate parameters to information needs for local adaptation to climate change. Climate 5(2):1-20. https://doi.org/10.3390/cli50 20025

Hasse J, Willen L (2019) Umfrage. Wirkung der Deutschen Anpassungsstrategie (DAS) für die Kommunen." Dessau-Roßlau. https://www.umweltbundesamt.de/sites/default/files/medien/1410/publi kationen/2019-01-21_cc_01-2019_umfrage-das.pdf. [last accessed 19 May 2020].

Heidrich O, Dawson RJ, Reckien D, Walsh CL (2013) Assessment of the climate preparedness of 30 urban areas in the UK. Clim Change 120(4):771-784. https://doi.org/10.1007/s10584-013-0846-9

Heidrich O, Reckien D, Olazabal M, Foley A, Salvia M, de Gregorio S, Hurtado HO et al (2016) National climate policies across Europe and their impacts on cities strategies. J Environ Manage 168:36-45. https://doi.org/10.1016/j.jenvman.2015.11.043

Hintz MJ, Luederitz C, Lang DJ, von Wehrden H (2018) Facing the heat: A systematic literature review exploring the transferability of solutions to cope with urban heat waves. Urban Climate 24:714727. https://doi.org/10.1016/j.uclim.2017.08.011

IPCC (Intergovernmental Panel on Climate Change) - Revi, Aromar, David E. Satterthwaite, Fernando Aragón-Durand, Jan Corfee-Morlot, Robert B.R. Kiunsi, Mark Pelling, Debra C. Roberts, William Solecki et al. (2014) Urban areas. In: C. B. Field, V. R. Barros, D. J. Dokken, K. J. Mach, M. D. Mastrandrea, T. E. Bilir et al. (eds.), Climate Change 2014: impacts, adaptation, and vulnerability. Part A:Global and Sectoral Aspects. Contribution of Working Group II to the Fifth Assessment Report of the Intergovernmental Panel on Climate Change (pp. 535-612.). Cambridge, New York: Cambridge University Press

Kareem B, Lwasa S, Tugume D, Mukwaya P, Walubwa J, Owuor S, Kasaija P, Sseviiri H, Nsangi G, Byarugaba D (2020) Pathways for resilience to climate change in African cities. Environ Res Lett 15(7):073002. https://doi.org/10.1088/1748-9326/ab7951

Khan A, Amelie V (2015) Assessing climate change readiness in seychelles: implications for ecosystembased adaptation mainstreaming and marine spatial planning. Reg Environ Change 15(4):721-733. https://doi.org/10.1007/s10113-014-0662-4

Kind C, Sartison K (2017) UBA-Studie: Wie deutsche Großstädte sich an den Klimawandel anpassen. https://www.umweltbundesamt.de/uba-studie-wie-deutsche-grossstaedte-sich-an-den. [last accessed 19 May 2020]

Kind C, Protze N, Savelsberg J, Lühr O, Ley S, Lambert J (2014) Entscheidungsprozesse zur Anpassung an den Klimawandel in Kommunen. Dessau-Roßlau: Umweltbundesamt. https://www.bmu.de/filea dmin/Daten_BMU/Pools/Forschungsdatenbank/fkz_3712_48_100_klimalotse_bf.pdf [last accessed 2 April 2021].

Klostermann J, van de Sandt K, Harley M, Hildén M, Leiter T, van Minnen J, Pieterse N, van Bree L (2018) Towards a framework to assess, compare and develop monitoring and evaluation of climate change adaptation in Europe. Mitig Adapt Strat Glob Change 23(2):187-209. https://doi.org/10. 1007/s11027-015-9678-4

Knieling J, Roßnagel A (2014) Governance der Klimaanpassung. Akteure, Organisation und Instrumente für Stadt und Region. Edited by Jörg Knieling and Alexander Roßnagel. oekom 
Kox T, Thieken AH (2017) To act or not to act? Factors influencing the general public's decision about whether to take protective action against severe weather. Weather Clim Soc 9(2): 299-315. https:// doi.org/10.1175/WCAS-D-15-0078.1

Kristine K, Niederhafner S, Stumpp I (2018) Fallstudienanalyse: Entwicklungspfade von Potsdam und Würzburg. In: Thieken, A et al. (eds): Urbane Resilienz gegenüber extremen Wetterereignissen - Typologien und Transfer von Anpassungsstrategien in kleinen Großstädten und Mittelstädten (ExTrass). Potsdam: Universität Potsdam. https://www.uni-potsdam.de/fileadmin/projects/extrass/ ExTrass_Abschlussbericht_Definitionsphase.pdf [last accessed 2 April 2021].

Kuhlicke C, Seebauer S, Hudson P, Begg C, Bubeck P, Dittmer C, Grothmann T, Heidenreich A, Kreibich H, Lorenz DF, Masson T, Reiter J, Thaler T, Thieken A, Bamberg S (2020) The behavioral turn in flood risk management, its assumptions and potential implications. - WIREs Water 7(3): e1418, https://doi.org/10.1002/wat2.1418

Le, Tu Dam Ngoc (2020) Climate change adaptation in coastal cities of developing countries: characterizing types of vulnerability and adaptation options. Mitig Adapt Strat Glob Change, 25(5), 739-761. https:// doi.org/10.1007/s11027-019-09888-z

Lesnikowski AC, Ford JD, Berrang-Ford L, Barrera M, Heymann J (2015) How are we adapting to climate change? A global assessment. Mitig Adapt Strat Glob Change 20(2):277-293. https://doi.org/10.1007/ s11027-013-9491-x

Meng M, Dabrowski M, Stead D (2020) Enhancing flood resilience and climate adaptation: The state of the art and new directions for spatial planning. Sustainability, 12(19). https://doi.org/10.3390/SU12197864

Milman A, Bunclark L, Conway D, Adger WN (2013) Assessment of institutional capacity to adapt to climate change in transboundary river basins. Clim Change 121(4):755-770. https://doi.org/10.1007/ s10584-013-0917-y

Nalau J, Verrall B (2021) Mapping the evolution and current trends in climate change adaptation science. Clim Risk Manag 32:100290. https://doi.org/10.1016/j.crm.2021.100290

Olazabal M, Gopegui MRD (2021) Adaptation planning in large cities is unlikely to be effective. Landsc Urban Plan 206:103974. https://doi.org/10.1016/j.landurbplan.2020.103974

Olazabal M, Galarraga I, Ford J, Murieta ESD, Lesnikowski A (2019a) Are local climate adaptation policies credible? A conceptual and operational assessment framework. International Journal of Urban Sustainable Development 11(3):277-296. https://doi.org/10.1080/19463138.2019.1583234

Olazabal, Marta, Maria Ruiz De Gopegui, Emma L. Tompkins, Kayin Venner, and Rachel Smith. 2019. A cross-scale worldwide analysis of coastal adaptation planning. Environmental Research Letters, 14(12). https://doi.org/10.1088/1748-9326/ab5532.

Olazabal, Marta, Sonia De Gregorio Hurtado, Eduardo Olazabal, Filomena Pietrapertosa, Monica Salvia, Davide Geneletti, D Alonzo, Efrén Feliú, Senatro Di Leo, and Diana Reckien (2014) How are Italian and Spanish cities tackling climate change? A local comparative study. Basque Centre for Climate Change (BC3) Working Paper Series

Reckien D, Flacke J, Dawson RJ, Heidrich O, Olazabal M, Foley A, Hamann JJP et al (2014) Climate change response in Europe: what's the reality? Analysis of adaptation and mitigation plans from 200 urban areas in 11 countries. Clim Change 122(1-2):331-340. https://doi.org/10.1007/s10584-013-0989-8

Reckien D, Flacke J, Olazabal M, Heidrich O (2015) The influence of drivers and barriers on urban adaptation and mitigation plans - an empirical analysis of European cities. PLoS ONE 10(8):1-21. https:// doi.org/10.1371/journal.pone.0135597

Reckien D, Salvia M, Heidrich O, Marco J, Pietrapertosa F, De Gregorio-hurtado S, Alonzo VD et al (2018) How are cities planning to respond to climate change ? Assessment of local climate plans from 885 Cities in the EU-28. J Clean Prod 191(2018):207-219. https://doi.org/10.1016/j.jclepro.2018.03.220

Romero-Lankao P (2012) Governing carbon and climate in the cities: An overview of policy and planning challenges and options. Eur Plan Stud 20(1):7-26. https://doi.org/10.1080/09654313.2011.638496

Salamanca A, Nguyen H (2016) Climate change adaptation readiness in the ASEAN countries https://www. sei.org/publications/adaptation-readiness-asean/. [last accessed 11 March 2021]

Salvia M, Reckien D, Pietrapertosa F, Eckersley P, Spyridaki N-A, Krook-Riekkola A, Olazabal M, et al. (2021) Will climate mitigation ambitions lead to carbon neutrality? An analysis of the local-level plans of 327 cities in the EU. Renewable and Sustainable Energy Reviews, 135(August 2020). https://doi. org/10.1016/j.rser.2020.110253

Schüle, Ralf, Miriam Fekkak, Rainer Lucas, and Uta von Winterfeld. (2016) Kommunen befähigen die Herausforderungen der Anpassung an den Klimawandel systematisch anzugehen (KoBe). https://www. umweltbundesamt.de/sites/default/files/medien/378/publikationen/climate_change_20_2016_kommu nen_befaehigen_die_herausforderungen_0.pdf. [last accessed 19 May 2020].

Shi L, Chu E, Debats J (2015) Explaining progress in climate adaptation planning across 156 U.S. municipalities. J Am Plann Assoc 81(3):191-202. https://doi.org/10.1080/01944363.2015.1074526 
Singh C, Madhavan M, Arvind J, Bazaz A (2021) Climate change adaptation in Indian cities: A review of existing actions and spaces for triple wins. Urban Climate 36:100783. https://doi.org/10.1016/j.uclim. 2021.100783

Thieken, Annegret, Julia Dierck, Antje Otto (2018) Deutschlandweiter Überblick zu städtischen Klimaschutz- und Klimaanpassungskonzepten. In Annegret Thieken et al. (eds) "Urbane Resilienz gegenüber extremen Wetterereignissen - Typologien und Transfer von Anpassungsstrategien in kleinen Großstädten und Mittelstädten ( ExTrass )." Potsdam. https://www.uni-potsdam.de/fileadmin/ projects/extrass/ExTrass_Abschlussbericht_Definitionsphase.pdf. [last accessed 19 May 2020].

Tilleard S, Ford JD (2016) Adaptation readiness and adaptive capacity of transboundary river basins. Clim Change 137(3-4):575-591. https://doi.org/10.1007/s10584-016-1699-9

UN-Habitat (2011) Local leadership for climate change action. Nairobi: United Nations Human Settlements Programme

United Nations (2018) World urbanization prospects: The 2018 Revision: Key Facts. 2018. https://popul ation.un.org/wup/Publications/Files/WUP2018-KeyFacts.pdf. [last accessed 19 May 2020]

van der Heijden J (2019) Studying urban climate governance: Where to begin, what to look for, and how to make a meaningful contribution to scholarship and practice. Earth System Governance 1:100005. https://doi.org/10.1016/j.esg.2019.100005

Voskamp IM, Van de Ven FHM (2015) Planning support system for climate adaptation: Composing effective sets of blue-green measures to reduce urban vulnerability to extreme weather events. Build Environ 83:159-167. https://doi.org/10.1016/j.buildenv.2014.07.018

Wamsler, Christine. 2015. "Guideline for Integrating Climate Change Adaptation into Municipal Planning and Governance." https://doi.org/10.13140/RG.2.1.2125.9369.

Wamsler C, Brink E, Rivera C (2013) Planning for climate change in urban areas: from theory to practice. J Clean Prod 50:68-81. https://doi.org/10.1016/j.jclepro.2012.12.008

Wamsler C, Wickenberg B, Hanson H, Olsson JA, Stålhammar S, Björn H et al (2020) Environmental and climate policy integration: Targeted strategies for overcoming barriers to nature-based solutions and climate change adaptation. J Clean Prod 247:119154. https://doi.org/10.1016/j.jclepro.2019.119154

Ye B, Jiang J, Liu J, Zheng Y, Zhou N (2021) Research on quantitative assessment of climate change risk at an urban scale: Review of recent progress and outlook of future direction. Renewable and Sustainable Energy Reviews, 135. https://doi.org/10.1016/j.rser.2020.110415

Publisher's note Springer Nature remains neutral with regard to jurisdictional claims in published maps and institutional affiliations. 